R. Landy, D. Perret, F. Watt, V. M. Corrigall, P. G. Winyard, P. Pozzilli, P. G. Conaghan, G. S. Panayi, L. Klareskog, P. Emery, and A. Nissim, Autoantibodies to posttranslationally modified type II collagen as potential biomarkers for rheumatoid arthritis. Arthritis Rheum., vol. 65, no. 7, pp. 1702-12, Jul. 2013.

Disclosure of Interest: None declared

DOI: 10.1136/annrheumdis-2017-eular.3498

\section{FRI0424 EQUAL PRESENCE OF CIRCULATING MAIT CELLS IN AXIAL SPA PATIENTS WITH ONLY AXIAL INVOLVEMENT AND AGE- AND SEX-MATCHED HEALTHY CONTROLS}

S. Arends, W. Abdulahad, A. Boots, B. Doornbos-van der Meer, E. Brouwer, A. Spoorenberg. Rheumatology and Clinical Immunology, University Medical Center Groningen, Groningen, Netherlands

Background: Previous studies indicated a potential role for mucosal-associated invariant $\mathrm{T}$ (MAIT) cells in the pathogenesis of ankylosing spondylitis (AS)., ${ }^{1,2}$ Active peripheral arthritis and extra-articular manifestations may influence the presence of circulating MAIT cells in AS.

Objectives: To investigate circulating MAIT cells in a homogenous group of axial spondyloarthritis (SpA) patients with only axial involvement in comparison to ageand sex-matched healthy controls $(\mathrm{HC})$. Secondly, to explore the association of MAIT cells with symptom duration and disease activity.

Methods: Consecutive axial SpA patients from the Groningen Leeuwarden axial SpA (GLAS) cohort without active peripheral arthritis, inflammatory bowel disease, psoriasis or uveitis were included. Patients with active infections or current use of biologics were excluded to rule out possible influence on the presence of circulating MAIT cells. Disease activity was assessed using ASDAS, BASDAI, and serum CRP levels.

The frequencies and absolute numbers of circulating MAIT cells were examined in peripheral blood of all studied samples by 5 -color flow cytometry. Immediately after sampling, EDTA-blood was stained with anti-CD3, anti-CD8, anti-TCRVa7.2, anti-CD161, and anti-TCRgd. After staining, the cells were washed, fixed, and analyzed immediately on FACS. MAIT cells were identified phenotypically as $\mathrm{CD}^{+}{ }^{+} \mathrm{CD} 8^{+} \mathrm{TCR} \gamma \delta^{-} \mathrm{V} \alpha 7.2^{+} \mathrm{CD} 161^{\text {high }}$ cells

Results: Of the 41 included axial SpA patients, mean age was $46 \pm 16$ years, $73 \%$ were male, mean symptom duration was $23 \pm 14$ years, and $78 \%$ were HLA-B27 positive. Mean ASDAS was 2.6 \pm 1.0 , mean BASDAI was $4.4 \pm 2.5$, and median CRP was 3 (range $2-30$ ). $70 \%, 54 \%$ and $37 \%$ of axial SpA patients had ASDAS $\geq 2.1, \mathrm{BASDAl} \geq 4$ or $\mathrm{CRP} \geq 5$, respectively. $\mathrm{HC}$ had exactly the same age and sex distribution.

Both the percentages and absolute numbers of circulating MAIT cells were comparable between axial SpA patients and HC (Figure 1). In axial SpA patients, absolute numbers of MAIT cells correlated negatively ( $\mathrm{rho}=-0.339$ ) with symptom duration. No significant associations were found between MAIT cells and disease activity, except for a negative correlation (rho=-0.332) between frequency of MAIT cells and BASDAI (Table 1). There were no significant differences in MAIT cells between axial SpA patients with and without active disease according to ASDAS, BASDAI or CRP.

Table 1. Association of percentages and absolute numbers of MAIT cells with symptom duration and assessments of disease activity in axial SpA patients $(n=41)$, Spearman correlation coefficients

\begin{tabular}{lcc}
\hline & $\%$ CD8+ MAIT & nr CD8+ MAIT \\
\hline Symptom duration $(\mathrm{yrs})$ & -0.248 & $-0.339^{\star}$ \\
ASDAS & -0.221 & 0.053 \\
BASDAI (0-10) & $-0.332^{\star}$ & -0.126 \\
CRP $(\mathrm{mg} / \mathrm{l})$ & -0.137 & 0.030 \\
\hline
\end{tabular}

${ }^{*}$-value $<0.05$

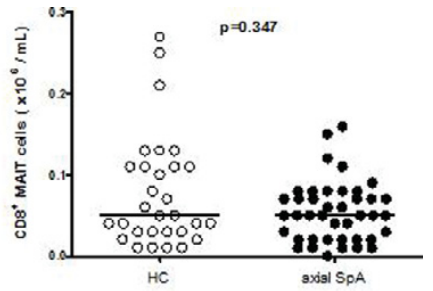

Figure 1. Percentages and absolute numbers of circulating CD8+ MAIT cells in axial SpA patients $(n=41)$ and matched healthy controls $(\mathrm{n}=30)$, Mann-Whitney $\mathrm{U}$ tests

Conclusions: In this homogeneous group of axial SpA patients with only axial disease, the presence of circulating MAIT cells did not differ from age- and sex-matched HC. No strong association was found between circulating MAIT cells and symptom duration or disease activity.

References:

[1] Gracey et al. Ann Rheum Dis 2016;75(12):2124-32.

[2] Hayashi et al. J Rheumatol 2016;43(9):1695-703.

Acknowledgements: Funding: This research project was supported by an unrestricted grant from Janssen. Janssen had no role in the design, conduct, interpretation, or publication of this study.
Disclosure of Interest: None declared

DOI: 10.1136/annrheumdis-2017-eular.6203

\section{FRI0425 ANALYSIS OF CELLULAR COMPOSITION AND CYTOKINE EXPRESSION IN THE SUBCHONDRAL BONE MARROW IN ANKYLOSING SPONDYLITIS}

E.E. Kenngott ${ }^{1}$, J. Bleil ${ }^{1}$, R. Maier ${ }^{2}$, J. Sieper ${ }^{1}$, U. Syrbe ${ }^{1} .{ }^{1}$ Rheumatology Campus Benjamin Franklin, Charité Universitätsmedizin Berlin; ${ }^{2}$ Experimental Rheumatology, Deutsches Rheuma-Forschungszentrum, Berlin, Germany

Background: Ankylosing spondylitis (AS) is characterized by inflammation within the sacroiliac joints and at the spine including vertebral bodies and facet joints. In AS, bone destruction is followed by new bone formation leading to ankylosis of joints and syndesmophyte development. Histological studies of bone material from AS patients showed subchondral bone marrow changes, namely the transition of the bone marrow into granulation tissue which facilitates subchondral bone destruction but also promotes local bone formation [1, 2]. Currently, it is unclear what promotes the transition of the bone marrow into the granulation tissue. Objectives: The aim of this study was to look for changes in the subchondral bone marrow in joints from AS patients that may precede and promote transformation into granulation tissue. Therefore, we analyzed the cellular composition of the bone marrow and determined local cytokine expression at subchondral regions of AS facet joints.

Methods: Facet joints were acquired from AS patients undergoing polysegmental correction surgery and compared to joints from autopsy controls. We performed immunohistochemical stainings to determine the number of T cells (CD3) and B cells (CD20), macrophages (CD68, CD163), monocytes (CD14), dendritic cells (DC; CD1a, DCsign) and myelopoietic cells (MPO). To correct for putative differences in fat cell content, software assisted image analysis was used to calculate the area of bone marrow covered by fat cells and the number of nucleated cells (DAPI) as well as myeloid cells. Cytokine expression was determined by mRNA in situ hybridization (TNF, IFNg) or immunohistochemistry (TGF $\beta$, IL-10). Results: We observed no difference in the number of adaptive immune cells, i.e. CD3+ $T$ and $C D 20+B$ cells, between AS and control joints and found no difference in T/B cell aggregates. Furthermore, no difference in the number of macrophages (CD163+, CD68+) and DCs (CD1a+, DCsign+) was found. The only difference in cellular composition appeared to be a slight trend towards a higher percentage of myelopoietic MPO+ cells/DAPI+ cells in AS joints compared to control joints. The overall number of DAPI+ cells as well as the fat content of the bone marrow was not different between AS and control joints.

Concerning cytokines, TNF mRNA expression was in general low but significantly increased $(p<0.05)$ in AS versus control joints. No difference was found for IFNg. The number of TGF $\beta$ expressing cells was similar in AS and control joints while the number of IL-10 positive cells was decreased $(p<0.01)$ in AS joints.

Conclusions: The results show a shift from pro-inflammatory to anti-inflammatory cytokine expression within subchondral bone marrow sites in AS joints while no major change in the cellular distribution of the major leukocyte subsets is found. The shift in cytokine milieu may contribute to transformation of the bone marrow into granulation tissue. It would be interesting to determine the cellular source of local cytokines, such as of IL-10.

References:

[1] Cruickshank B. Lesions of cartilaginous joints in ankylosing spondylitis. The Journal of pathology and bacteriology 1956;71(1):73-84.

[2] Bleil J, Maier R, Hempfing A, Sieper J, Appel H, Syrbe U. Granulation Tissue Eroding the Subchondral Bone Also Promotes New Bone Formation in Ankylosing Spondylitis. Arthritis Rheumatol 2016;68(10):2456-65.

Disclosure of Interest: None declared

DOI: 10.1136/annrheumdis-2017-eular.3173

\section{FRI0426 NO DEMONSTRABLE EFFECT OF IL-23 RECEPTOR VARIANTS ON CLINICAL MEASURES AND IL23/ IL-17 LEVELS IN ANKYLOSING SPONDYLITIS}

J. Nossent ${ }^{1,2}$, S. Johnsen ${ }^{3}$, G. Bakland ${ }^{2,4}{ }^{1}$ School of Medicine, University of Western Australia, Crawley, Australia; ${ }^{2}$ Bone and Joint Group, Arctic University, Tromso; ${ }^{3}$ Norwegian University of Life Sciences, Ås; ${ }^{4}$ Rheumatology, University Hospital North Norway, Tromso, Norway

Background: IL23 binding to IL23 receptor (IL23R) is necessary for the maturation of Th17 cells and generation of proinflammatory IL17 and TNF in AS. IL23R variants have considerable impact on AS susceptibility in genome-wide association studies.

Objectives: To describe the effect of genotypic IL23R variants on proinflammatory cytokines and disease measures in AS.

Methods: Cross sectional cohort study of patients with established AS ( $n=334$, $90 \%$ B27 +, mean age at study 45 years) included in a disease registry. IL23R genotyping for nonsynonymous SNP's (rs11209026 (protective allele A) and rs11209032 (risk allele A) was done by Taqman RT-PCR, while IL23, IL17, IL6 and TNF levels determined by sandwich ELISA and compared with age and gender matched healthy controls $(n=72)$. Genotypic associations with clinical and serological features were analyzed with nonparametric methods.

Results: There was no significant difference between in AS patients and controls 